\title{
Extraction of Trace Copper(II) in Water Samples using Ammonium Pyrrolidine Dithiocarbamate(APDC) Modified Carbon Nanotubes to Measurement by FAAS
}

\author{
HOSSAIN AREFAZAR $^{1 *}$ and ALI MOGHIMI² \\ 'Department of Physics, South Tehran Branch Islamic Azad University, Tehran, Iran. \\ ${ }^{2}$ Department of Chemistry, Varamin( Pishva )Branch Islamic Azad University, Varamin, Iran. \\ ${ }^{*}$ Corresponding author E-mail: dharefazar@yahoo.com, alimoghimi@iauvaramin.ac.ir \\ http://dx.doi.org/10.13005/ojc/320537
}

(Received: July 15, 2016; Accepted: September 25, 2016)

\begin{abstract}
In this method to amounting of the trace amount of $\mathrm{Cu}$ (II) ions in aqueos Samples by CNT modified Amino-pyrrolidine dthiocarbamate (APDC) which in order to improve the performance of extraction and preconcentration was used. Amounting of the ions density in solution was performed by the method of flame atomic absorption spectrometry. The effective parameters on extraction such as: effect of $\mathrm{pH}$, the amount and eluent solvent, time of extraction and effect of other cation were optimized. Concentrate factor was found 57 and LOD method of limit of detection was found to 0 . $6 \mu \mathrm{g} \cdot \mathrm{L}^{-1}$. the relative standard deviation is $0.76 \%(\mathrm{RSD} \%)$.
\end{abstract}

Keywords: Copper(II), Preconcentration, Amino-pyrrolidine dthiocarbamate (APDC), extraction, carbon nanotubes, FAAS.

\section{INTRODUCTION}

Copper at trace concentrations acts as both a micronutrient and a toxicant in marine and fresh water systems ${ }^{1-6}$. This element is needed by plants at only very low levels and is toxic at higher levels. At these levels, copper can bind to the cell membrane and hinder the transport process through the cell wall. Copper at nearly $40 \mathrm{ng} \mathrm{mL}^{-1}$ is required for normal metabolism of many living organisms ${ }^{7-10}$. On the other hand, copper is an important element in many industries. Thus, the development of new methods for selective separation, concentration and determination of it in sub-micro levels in different industrial, medicinal and environmental samples is of continuing interest. The determination of copper is usually carried out by flame and graphite furnace atomic absorption spectrometry $(\mathrm{AAS})^{11,12}$ as well as spectrometric methods ${ }^{13}$, 14. However, due to the presence of copper in medicinal and environmental samples at low levels, its separation from other elements presents and 
also the use of a preconcentration step prior to its determination is usually necessary.

Different methods, especially Liquid- Liquid extraction of copper in the presence of various classical ${ }^{15-19}$ and macrocylic ${ }^{20,21}$ co-extractant ligands has attracted considerable attention. However, the use of classical extraction methods for this purpose is usually time-consuming, labor-intensive and requires large amounts of high purity solvents for extraction. Nevertheless, several other techniques for the preconcentration and separation of copper have been proposed including liquid chromatography ${ }^{22}$ supercritical fluid extraction ${ }^{23}$, flotation ${ }^{24}$, aggregate film formation ${ }^{25}$, liquid membrane ${ }^{26}$, column adsorption of pyrocatechol violet-copper complexes on activated carbon $^{27}$, ion pairing ${ }^{28}$, ion pairing ${ }^{29}$, preconcentration with yeast ${ }^{30}$, and solid phase extraction using $C_{18}$ cartridges and disks ${ }^{31}$.

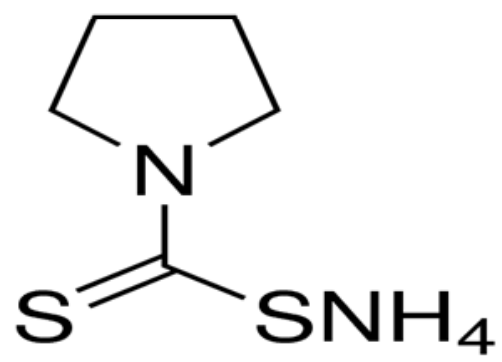

Schematic 1: Structure of Schiff's Ammonium Pyrrolidine Dithiocarbamate(APDC)
Solid phase extraction (SPE) or liquidsolid extraction is poplar and growing techniques that are used to sample preparation for analysis. It is an attractive alternative for classical liquid-liquid extraction methods that reduce solvent usage and exposure, disposal costs and extraction time for sample separation and concentration purposed ${ }^{32}$.

Chitosan has been reported to be a suitable biopolymer for the removal of heavy metals from industrial wastewater, due to its high amino and hydroxyl functional group content, low toxicity, biocompatibility, and biodegradability 33. However, to improve its absorption capacity and enhance the separation rate, the design and synthesis of novel adsorbents are still critical ${ }^{34}$. The

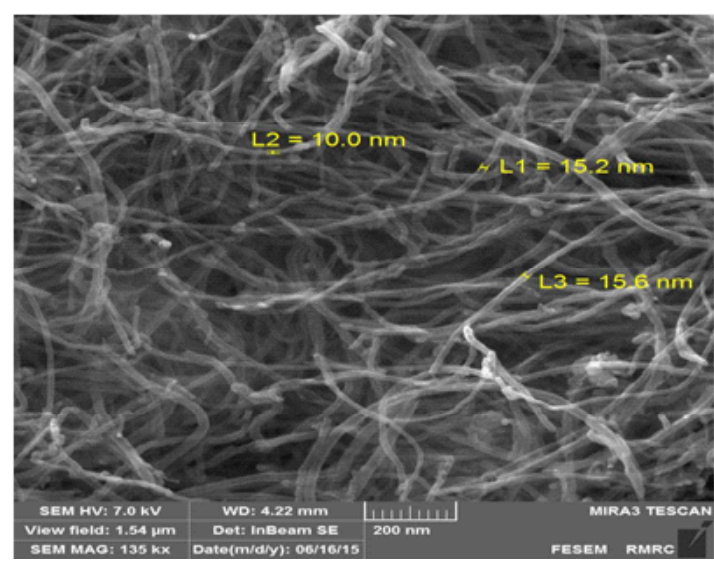

Fig. 1: SEM image of Multi walled carbon nanotubes (SWCNTs)

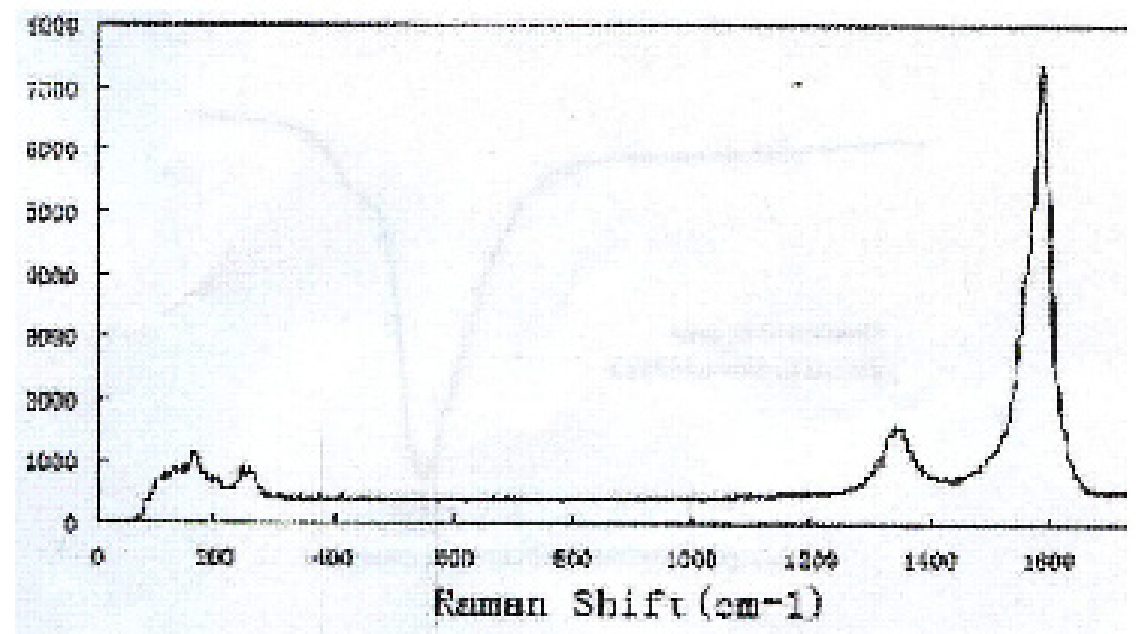

Fig. 2: Raman Spectroscopy of Multi walled carbon nanotubes (MWCNTs) 
application of magnetic adsorbent technology to solve environmental problems is a relatively new and emerging field of research. Coating chitosan with magnetic fluids is a new method to improve separation speed, and the method has been reported that it can improve the surface area for adsorption and reduce the required dosage for the adsorption of heavy metals.

Actually, the SPE technique using graphene and derivates of graphene such as functionalization graphene oxide as a novel and great adsorbent $\mathrm{t}^{39}$. This present work preconcentration of $\mathrm{Cu}^{2+}$ based on the adsorption of its Ammonium Pyrrolidine Dithiocarbamate(APDC) complex on an Multi walled carbon nanotubes (MWCNTs). The adsorbed complex could be eluted using environmentally and the concentration of $\mathrm{Cu}^{2+}$ was determined by FAAS. The influence of various experimental parameters such as acidity, sample volume, flow rate, diverse ions, etc. was examined in detail. The validity of the proposed method was tested in tap water samples and waste water.

\section{EXPERIMENTAL}

\section{Instrumentation}

Determination of $\mathrm{Cu}^{2+}$ by PG-990 flame atomic absorption spectrometer equipped with $\mathrm{HI}-\mathrm{HCl}$ according to the recommendations of the manufacturers. These condition are tabulated in ( Table 3). The $\mathrm{pH}$ measurements used by Sartorius model PB-11.

\section{Chemicals and reagents}

Multi walled carbon nanotubes (MWCNTs), Schiff's Ammonium Pyrrolidine Dithiocarbamate(APDC) were prepared from Darmstadt, Germany of Merck, Method and dried for a week over phosphorus pentoxide in a vacuum desiccators before use. 4-Isocyanatobenzenesulfonyl azide was prepared from 4-carboxybenzenesulfonyl

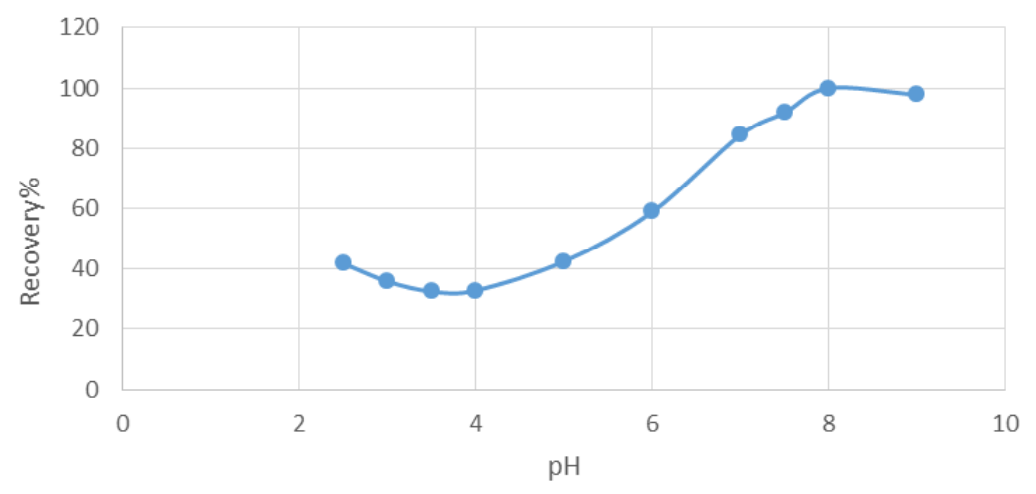

Fig. 3: Recovery percentage of $\mathrm{Cu}(\mathrm{II})$ against $\mathrm{pH}$

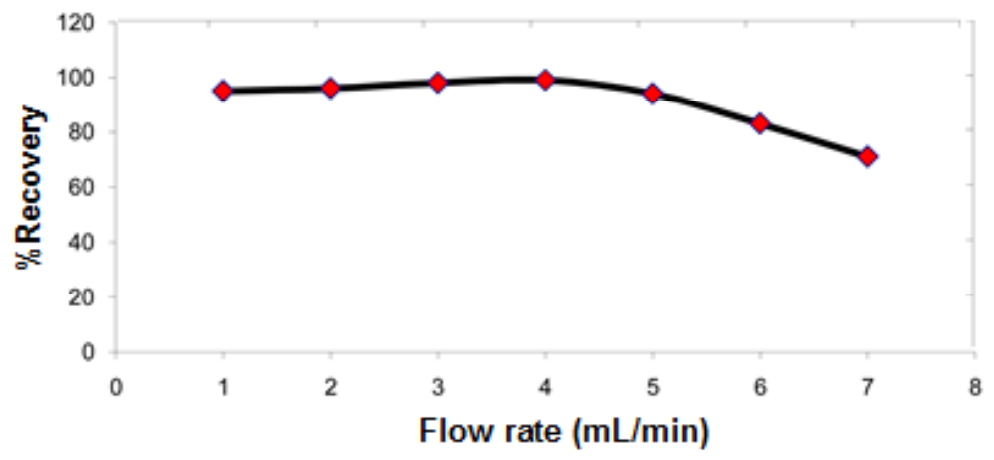

Fig. 4: Flow rates of the sample solutions on the recovery percentage of Copper(II) 
azide via a published procedure ${ }^{17}$. All solutions were prepared with doubly distilled deionized water from Darmstadt, Germany of Merck. $\mathrm{C}_{18}$ powder for chromatography with diameter of about $50 \mu \mathrm{m}$ obtained from Katayama Chemicals from Supelco. It was conditioned before use by suspending in $4 \mathrm{M}$ nitric acid for $20 \mathrm{~min}$, and then washed two times with water.

Preparation of Multi walled carbon nanotubes (MWCNTs) cartridge

A column $1.5 \mathrm{~cm}$ in diameter and 15 $\mathrm{cm}$ in length was used for the preconcentration of Copper(II). About $5 \mathrm{~g}$ of Multi walled carbon nanotubes cartridge was mixed with $25 \mathrm{~mL}$ of $\mathrm{HCl}$ $1 \mathrm{M}$ to form slurry and then loaded on to the column. Cotton was placed at the bottom for allowing Multi walled carbon nanotubes (MWCNTs) cartridge to settle properly. The column was packed up to a height of $3 \mathrm{~cm}$.

\section{Procedure for present method}

$30 \mathrm{mg}$ Ammonium Pyrrolidine Dithiocarbamate(APDC) and $50 \mathrm{mg}$ SDS of $50 \mathrm{~mL}$ was loaded on to the column of neutral Multi walled carbon nanotubes (MWCNTs) cartridge maintaining a flow rate of $8 \mathrm{~mL} \mathrm{~min}^{-1}$. Then $10 \mu \mathrm{gm} \mathrm{Cu}(\mathrm{II})$ solution of $250 \mathrm{ml}$ volume was loaded on to the column. The sample solution was uploading on to the column of neutral Multi walled carbon nanotubes (SWCNTs) cartridge maintaining a flow rate of $0.5 \mathrm{~mL} \mathrm{~min}^{-1}$. The desorption complex and eluted using $10 \mathrm{~mL}$ of $\mathrm{HNO}_{3}$ $4 \mathrm{M}$ at a flow rate of $0.5 \mathrm{~mL} \mathrm{~min}^{-1}$ and the concentration of Copper(II) was determined by FAAS.

Table 1: Effect of diverse ions on the recovery of $10 \mu \mathrm{g} \mathrm{Cu}(\mathrm{II})$ in a sample volume of $100 \mathrm{~mL}$

\begin{tabular}{lcc}
\hline Ions & $\begin{array}{c}\text { added } \\
(\mathbf{m g})\end{array}$ & $\begin{array}{c}\text { (\%)Recovery } \\
\text { of Copper (II) }\end{array}$ \\
\hline $\mathrm{K}^{+}$ & 11 & $98.3(0.3) \mathrm{a}$ \\
$\mathrm{Ca}^{+}$ & 0.02 & $98.6(0.6)$ \\
$\mathrm{Mg}^{+}$ & 1.05 & $99.3(0.9)$ \\
$\mathrm{Na}^{+}$ & 0.11 & $99.4(1.1)$ \\
$\mathrm{Zn}^{+}$ & 1 & $99.5(1.2)$ \\
$\mathrm{Cl}^{-}$ & 0.09 & $99.6(0.8)$ \\
$\mathrm{NO}_{3}^{-}$ & 0.5 & $98.1(1.3)$ \\
$\mathrm{SO}_{4}{ }^{2-}$ & 0.16 & $97.8(0.6)$ \\
$\mathrm{CH}_{3} \mathrm{COO}^{-}$ & 0.1 & $99.2(1.1)$ \\
$\mathrm{Cr}_{2} \mathrm{O}_{7}^{2-}$ & 0.15 & $99.1(0.6)$ \\
\hline
\end{tabular}

a: Values in parenthesis are CVs based on three individual replicate measurements

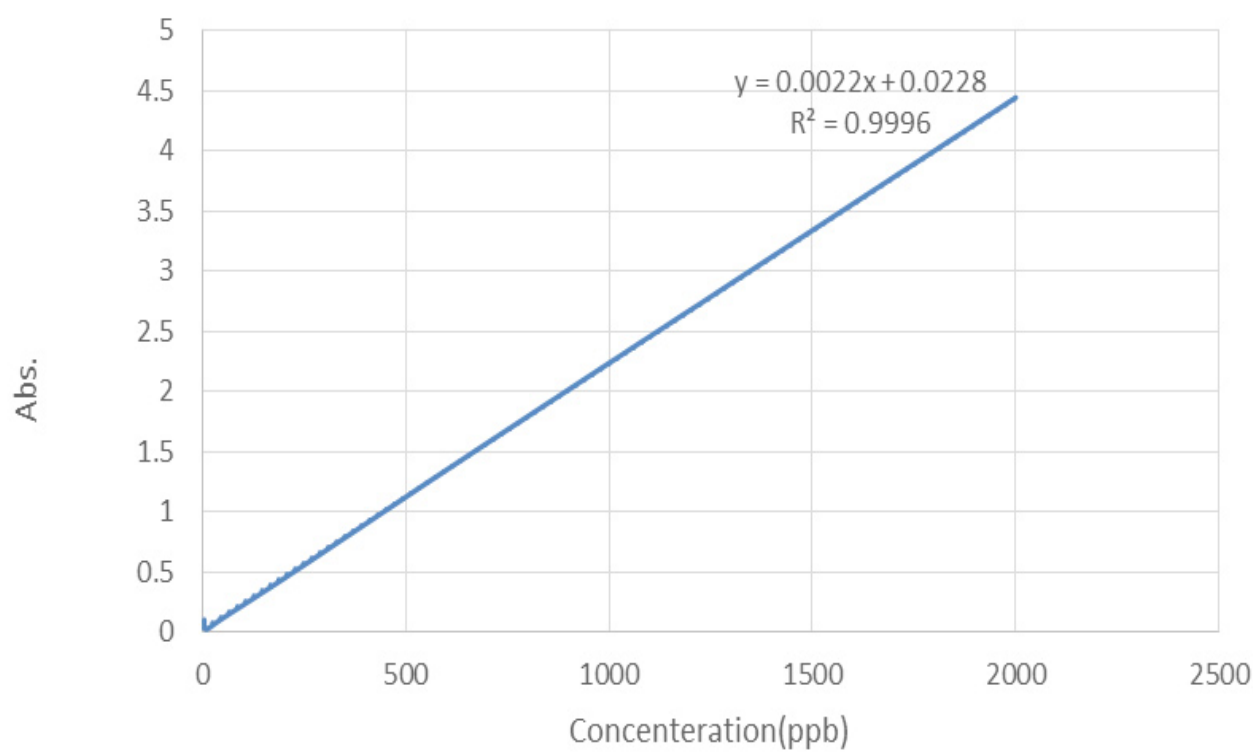

Fig. 5: Calibration curve of Copper(II) measured by SPE-AAS 


\section{RESULTS AND DISCUSSION}

Fig.1. show the morphology and size of Multi walled carbon nanotubes (MWCNTs) modified by Ammonium Pyrrolidine Dithiocarbamate(APDC) sorbent as shown in Fig. 1. sorbent retained a homogenous distribution in the range of 156.0$10.0 \mathrm{~nm}$. Fig.2.The formation of MWCNTs was followed by Raman Spectroscopy spectroscopy the carbonyl vibration appears at $1580 \mathrm{~cm}^{-1}$, while there are fingerprints at $160 \mathrm{~cm}^{-1}$ and $230 \mathrm{~cm}^{-1}$ due to the presence of hydroxyl species at the carbon nanotubes ${ }^{23}$.

\section{Factor of $\mathrm{pH}$ in Preconcentration}

The factor of $\mathrm{pH}$ of the aqueous solution on the extraction of $100 \mathrm{ng}$ of each of the cations
$\mathrm{Cu}$ (II) was studied in the $\mathrm{pH}$ rang of 1-10. The effect $\mathrm{pH}$ of the solution was adjusted by means of either $0.01 \mathrm{M} \mathrm{H} \mathrm{NO}_{3}$ or $0.01 \mathrm{M} \mathrm{NaOH}$. The best of recovery Was obtained indicate that complete chelation and recovery of $\mathrm{Cu}(\mathrm{II})$ occurs in $\mathrm{pH}$ range of $6-8$ and that of in 2-9 and are shown in Fig. 3 . It is probable that at higher $\mathrm{pH}$ values, the cations might be hydrolysed and complete desorption occur. Hence, $\mathrm{pH}=8.0$ in order to prevent hydrolysis of the cations and also keeping on the cartridge $\mathrm{C}_{18}$, was chosen for further research.

\section{Choice of the eluent}

A reagents were tested in order to desorption complex from the column. In order to choose the most effective eluent for the quantitative recovery of Copper(II), methanol, ethanol, acetone, $\mathrm{HCl} 1 \mathrm{M}, \mathrm{HCl}$

Table 2: Analytical results for the recovery of $\mathrm{Cu}(\mathrm{II})$ in water samples

\begin{tabular}{lccc}
\hline Sample & $\begin{array}{c}\mathrm{Cu}(\mathrm{II}) \\
\text { added }(\boldsymbol{\mu g})\end{array}$ & $\begin{array}{c}\text { Found of Cu(II) } \\
\text { with FAAS }(\boldsymbol{\mu g})\end{array}$ & $\begin{array}{c}\text { GF-AAS } \\
(\boldsymbol{\mu g})\end{array}$ \\
\hline Tap Water & 0 & $0.002(0.4)^{\mathrm{a}}$ & $0.004(0.7)$ \\
& 15 & $17.20(0.7)$ & $17.16(0.9)$ \\
Ground water & 20 & $23.12(0.3)$ & $22.98(0.6)$ \\
& 0 & $1.23(0.2)$ & $1.41(0.3)$ \\
Waste water & 10 & $21.72(0.1)$ & $21.93(0.2)$ \\
& 20 & $29.81(0.8)$ & $29.78(0.7)$ \\
Synthesis sample & 0 & $3.92(0.8)$ & $3.86(0.7)$ \\
$0.2 \mathrm{mg}^{2} \mathrm{Co}^{2+}, \mathrm{Cd}^{2+}$, & 10 & $9.63(0.9)$ & $9.76(0.8)$ \\
$\mathrm{Na}^{+} \mathrm{Al}^{3+}, \mathrm{Ba}^{2+}, \mathrm{Ca}^{2+}$ & 20 & $17.86(0.6)$ & $17.21(0.2)$ \\
& 5 & N.D & $\mathrm{N} . \mathrm{D}$ \\
& $15.82(0.8)$ & $15.75(0.9)$ \\
& $26.27(0.2)$ & $26.49(0.6)$ \\
\end{tabular}

a: Values in parenthesis are CVs based on three individual replicate measurements

b: Not Detection

Table 3: The conditions of flame for determination of Copper

Slit width

Operation current of HI-HCL

Resonance fine

Type of background correction

Type of flame

Air flow

Acetylene flow

\section{$0.7 \mathrm{~nm}$}

$5.0 \mathrm{~mA}$

283.3nm

Deuterium lamp

Air/acetylene

7.0 mL. $\mathrm{min}^{-1}$

$1.7 \mathrm{~mL} \cdot \mathrm{min}^{-1}$
$3 \mathrm{M}, \mathrm{H}_{3} \mathrm{PO}_{4} 1 \mathrm{M}$, and Acidified solvents obtained by addition of $\mathrm{HNO}_{3} 4 \mathrm{M}$, were studied. The recovery of Copper(II) was found to be quantitative with ethanol and $\mathrm{HNO}_{3} 4 \mathrm{M}$ as eluting agents. However, $\mathrm{HNO}_{3} 4 \mathrm{M}$ was preferred owing to its non-inflammability and less toxicity ${ }^{16,17}$. It was observed that when the ratio of $\mathrm{HNO}_{3} 4 \mathrm{M}$ a recovery of $99.8 \%$.

\section{Effect of sample volume}

The recovery of the analyte was researched in the range $100-1500 \mathrm{~mL}$ maintaining an overall 
concentration of $0.025 \mathrm{~mol} \mathrm{~L}^{-1}$ sulfuric acid. The resulting complex was eluted using $10 \mathrm{~mL}$ of $\mathrm{HNO}_{3}$ $4 \mathrm{M}$. As can be seen from the figure, it is evident that the recovery of copper(II) is more than $97 \%$ up to $250 \mathrm{~mL}$ sample volume. A preconcentration factor of 57 could be attained for more than $97 \%$ of $\mathrm{Cu}(\mathrm{II})$ when the sample volume was $250 \mathrm{~mL}$.

\section{Effect of flow rate}

The flow rate suitable for optimum loading of $\mathrm{Cu}(\mathrm{II})$ Ammonium Pyrrolidine Dithiocarbamate(APDC) complex on the Multi walled carbon nanotubes (MWCNTs) cartridge. This could be probably due to the insufficient contact time between the sample solution and Multi walled carbon nanotubes (MWCNTs) cartridge. A flow rate of $5 \mathrm{~mL}$ $\mathrm{min}^{-1}$ was maintained for the elution of copper(II) Fig 4.

\section{Precision studies and limit of detection}

Under optimized conditions, a calibration curve for $\mathrm{Cu}$ (II) was found by preconcentrating a series of $\mathrm{Cu}$ (II) standards according to the procedure mentioned. The curve was linear from $1.0 \mathrm{mg} / \mathrm{l}$ to $7.0 \mathrm{mg} / \mathrm{l}$ for $\mathrm{Cu}$. As analytical figures of merit, The limit of detection was found to be $0.1 \mu \mathrm{g} \cdot \mathrm{mL}^{-1}$.

\section{Effect of foreign ions}

The influence of common foreign ions on the adsorption of $\mathrm{Cu}$ (II) on CNT modified Aminopyrrolidine dthiocarbamate (APDC) were studied. In these work, $50.0 \mathrm{ml}$ solutions containing $5 \mathrm{ppm}$ of $\mathrm{Cu}$ and various amounts of interfering ions were treated according to the suggested procedure. The tolerance level was defined as the maximum concentration of the foreign ion causing a change in the analytical signal no higher than $5 \%$, when compared with the signal of 5ppm copper alone. The results, listed in Table 1 demonstration that the presence of major cations and anions in natural water has no important influence on the adsorption of $\mathrm{Cu}$ (II) ions under the designated conditions.

\section{Recovery studies in real sample}

The accuracy of the proposed method was tested by spiking known concentrations of copper(II) to tap water(Tehran, taken after 10 min operation of the tap), and rain water (Tehran, 21 Jun, 2016) samples. The water samples were filtered and stored in PET bottles. The recovery of Copper(II) was found to be satisfactory with a relative standard deviation of $5 \%$ for 3 replicate measurements and the results are shown in Table 2.

\section{Comparison with other solid phase adsorbents}

The present method was compared to a variety of solid adsorbents reported recently in the literature. Also, the proposed method was free of interference compared to conventional procedures to determine Copper ${ }^{46,51,52}$. As can be seen from the references, it is evident that the preconcentration factor obtained with Multi walled carbon nanotubes (MWCNTs) cartridge is comparable to or even better than most of the other chelating matrices. The significant feature of the proposed method is the use of water samples benign $\mathrm{HNO}_{3} 4 \mathrm{M}$ for the elution of the complex.

\section{Calibration curve}

The calibration curve of Copper(II) solutions is represented in Fig.5 and the related regression is $\mathrm{Y}=0.0022 \mathrm{X}+0.0228$ providing a correlation coefficient of $R^{2}=0.9996$.

\section{CONCLUSIONS}

The proposed SPE method possesses advantages such as easiness, and considerable selectivity in comparison with the previously reported procedures for isolation and determination of $\mathrm{Cu}^{2+}$ contents ${ }^{46,51,52}$. In conclusion, the proposed SPE possesses the following advantages: the technique is rapid when compared with the previously reported procedures for the separation and determination of copper, the time taken for the separation and determination of copper in a $500 \mathrm{~mL}$ sample is at the most $30 \mathrm{~min}$. Furthermore, it is a simple, highly sensitive, selective and reproducible method for the separation of $\mathrm{Cu}^{2+}$ and in this work the recovery yields obtained with CNT modified Amino-pyrrolidine dthiocarbamate (APDC) were about $95-100 \%$ then it show derivation e.g. in this work CNT modified Amino-pyrrolidine dthiocarbamate (APDC) is full of potential for use as a adsorbent in the extraction method like SPE and SPME consequently it can be applied to the preconcentration and determination of copper and the large number of heavy metal that are dangers for human from real samples. 


\section{ACKNOWLEDGMENTS}

We gratefully acknowledge financial of department of chemistry, department of Varamin branch Islamic Azad University for financial support.

\section{REFERENCES}

1. Filik H., Ozturk B.D., Dogutan M., Gumus G., Apak R., Talanta 1997.,44., 877.

2. Kokal, V. Synek, P. Jano, Talanta 2002., 58 325.

3. Locatelli C., Torsi G., Microchem. J. 2004., 78., 175.

4. Kulichenko S.A., Doroschuk V.O., Lelyushok S.O., Talanta 2003, 59 .,767.

5. Kagaya S., Araki, Y. Hasegawa Z.A., Anal. Sci. 2002, 18923.

6. Moghimi A. Journal of Chemical Health Risks 2014, 4(2), 15-22.

7. Moghimi A. , Russian Journal of Physical Chemistry, 2013., A 87(11) 1851-1858.

8. Moghimi A; Orient. J. Chem. 2006, 22(3), 527.

9. Nayebi P.,, Moghimi A..; Orient. J. Chem 2006.,22(3), , 507.

10. Moghimi A, Chinese Journal of Chemistry 2007, 25 .,640.

11. Moghimi A, Chinese Journal of Chemistry 2007, 25 (10), 1536.

12. Moghimi A, Russian Journal of Physical Chemistry 2013 A,87(7) 1203-1209.

13. Welcher F.J., Boschmann E., Organic Reagents for Copper, Krieger Huntington, New York,1979.

14. Marczenko Z., Separation and Spectrophotometric Determination of Elements, Ellis Horwood, London, 1986.

15. Bharagava O.P, Talanta 1969., 16.,743.

16. Schilt A.A., Hoyle W.C., Anal. Chem. 1964., 41.,344.

17. Borchart L.G, Butler J.P., Anal. Chem. 1957, 29.,414.

18. Chaisuksant R.,. Ayuthaya W.P, Grudpan K., Talanta 2000.,53.,579.

19. Kara D., Alkan M., Microchem. J. 2002.,71 29.

20. Saito K.,.Murakami S, Muromatsu A., Sekido E., Anal.Chim. Acta 1994., 294.,329.

21. Ikeda K., Abe S., Anl.Chim. Acta 1998., 363
., 165 .

22. Igarashi S., Ide N., Takagai Y., Anal.Chim. Acta 2000., 424.,263.

23. Liu J., Wang W., Li G., Talanta 2001.,53.,1149.

24. Anthemidis A.N.,. Zachariadis G.A., Stratis J.A, Talanta 2001.,54.,935.

25. Zenedelovska D., Pavlovska G., Cundeva K., Stafilov T., Talanta 2001.,54.,139.

26. Liang H.D., Han D.M.,Anal.Lett. 2006.,39 .2285-2295.

27. Campderros M.E., Acosta A., Marchese J., Talanta 1998., 47.,19.

28. Narin I., Soylak M., Elic L.,.Dogan M, Talanta 2000.,52.,1041.

29. Akama Y., Ito M., Tanaka S., Talanta 2000.,52.,645.

30. Ohta K,. Tanahasi H, Suzuki T., Kaneco S., Talanta 2001.,53.,715.

31. Cuculic V, Mlakar M., Branica M., Anal. Chim. Acta 1997.,339.,181.

32. Moghimi A, Tehrani M.S., Waqif S. Husain, Chinese Journal of Chemistry in press.

33. Y.H Li., Di Z., Ding J., Wu D., Luan Z., Zhu Y., Adsorption thermodynamic, kinetic and desorption studies of $\mathrm{Pb}^{2+}$ on carbon nanotubes, Water Res. 2005, 39., 605.

34. Rao G.P., Lu C., Su F., Sorption of divalent metal ions from aqueous solution by carbon nanotubes: a review, Sep. Purif. Technol. 2007., 58 .,224.

35. Depan D., Girase B., Shah J.S., Misra R.D.K., Structure-process-property relationship of the polar graphene oxide-mediated cellular response and stimulated growth of osteoblasts on hybrid chitosan network structure nanocomposite scaffolds, Acta Biomater. 2011., 73432-3445.

36. Izatt R.M., Bradshaw J.S., Bruening R.L., Pure Appl. Chem. 1996.,68.,1237.

37. Hagen D.F.,.Markell C.G,. Schmitt G.A, Anal. Chim. Acta 1990.,236.,157. 
38. Krueger C.J., Fild J.A., Anal.Chem. 1995.,67.,3363.

39. Taylor K.Z.,.Waddell D.S,.Reiner E.J,Anal. Chem. 1995.,67.,1186.

40. Berijani, S.; Assadi, Y.; Anbia, M.; Milani Hosseini, M.R. ; Aghaee, E.; J. Chromatogr. A 2006, 1123,1 .

41. Rahnama Kozani, R.; Assadi, Y.; Shemirani, F.; Milani Hosseini, M.R. ; Jamali, M.R.; Talanta, in press.

42. Nayebi P.,; MOGHIMI A., Orient.J. Chem.2006,22(3),507.

43. Manzoori J.L., Sorouradin M.H., Shabani A.M.H.,Microchem. J. 1999., 63 .,295-301.

43. Taher M.A., Puri S., Bansal R.K., Puri B.K., Talanta.,1997., 45.,411-416.

45. Shemirani F., Abkenar S.D., J. Anal. Chem.
2004., 59 (4) .,327-330.

46. Taher M.A., Turk. J. Chem. 2003, 27 .,529537.

47. Manzoori J.L., Karim-Nezhad G., Anal. Sci. 2003., 19 (4) .,579-583.

48. Bermejo-Barrera P.,. Nancy M.A, Cristina D.L., Adela B.B., Microchim.Acta .,2003., 142 (1-2) 101-108.

49. Moghimi Ali; Orient.J.Chem. 2006,22(3),527.

50. Moghimi Ali.; Ghammamy S. "Environmental chemistry an Indian journal'2007,.2, 3.

51. Choi,Y.S.;Choi,H.S.Bull.Korean Chem. Soc. 2003.,24.,222.

52. Saber Tehrani,M.; Rastegar,F.; Parchehbaf, A.;Rezvani,Z.; Chinese Journal of Chemistry 2005.,23.,1437. 